\title{
Characterization of Dermal Dendritic Cells in Psoriasis \\ Autostimulation of T Lymphocytes and Induction of Th1 Type Cytokines
}

Frank O. Nestle, ${ }^{\star}$ Laurence A. Turka, ${ }^{\star}$ and Brian J. Nickoloff*

*Departments of Pathology and ${ }^{\ddagger}$ Internal Medicine, University of Michigan Medical School, Ann Arbor, Michigan 48109

\section{Abstract}

Local activation of $T$ lymphocytes is regarded as an important immunological component of psoriatic skin lesions. Within psoriatic plaques (PP) there are large numbers of dermal dendritic cells (DDCs) immediately beneath the hyperplastic epidermis surrounded by $T$ cells. In this study we investigated the ability of DDCs isolated from PP skin to support immune responses of resting peripheral blood $T$ cells. For comparison, other dendritic cells were obtained from blood of the same psoriatic patients, as well as DDCs from skin of normal healthy individuals (designated NN skin). All dendritic cells studied had high surface expression of HLA-DR, B7, and lymphocyte function associated antigen-1 molecules. $T$ cell proliferative responses and cytokine production profiles to these various dendritic cells were measured in the absence and presence of PHA or bacterialderived superantigens. In the absence of exogenous mitogens, PP skin-derived DDCs were much more effective stimulators of spontaneous $T$ cell proliferation compared with either psoriatic blood-derived or NN skin-derived dendritic cells. Antibody blocking studies revealed involvement of HLA-DR, B7, and lymphocyte function associated antigen-1 on PP skin-derived DDCs. Cytokine profiles revealed that in the absence of exogenous stimuli PP skinderived DDCs mediated a $T$ cell response with high levels of IL-2 and IFN- $\gamma$, but not IL-4 or IL-10. NN skin-derived DDCs produced a similar qualitative response, but quantitative amounts of all cytokines measured were lower. Upon addition of PHA or superantigens, both PP skin-derived and NN skin-derived DDCs mediated high levels of IL-2 and IFN- $\gamma$ production, with induction of IL-4 particularly evident for PHA reactions. Addition of conditioned medium from psoriatic dermal fragments did not enhance the autostimulatory capacity of blood-derived dendritic cells. These findings highlight the potent autostimulatory potential of PP skin-derived DDCs and suggest an important immunological contribution for these previously overlooked cell types contained within lesional skin sites. (J. Clin. Invest. 1994. 94:202-209.) Key words: psoriasis - T lymphocytes • dendritic cells $\bullet$ cytokines $\cdot$ autoimmunity

Address correspondence to Dr. Brian J. Nickoloff, Department of Pathology, University of Michigan, M4232 Medical Science I, 1301 Catherine Street, Ann Arbor, MI 48109-0602.

Received for publication 18 November 1993 and in revised form 27 January 1994.

J. Clin. Invest.

(c) The American Society for Clinical Investigation, Inc.

0021-9738/94/07/0202/08 \$2.00

Volume 94, July 1994, 202-209
Introduction

Psoriasis is a common, well-defined skin disease featuring the interplay of genetic, environmental, and immunological factors (1). Psoriasis is listed among other chronic diseases believed to be of autoimmune origin, such as multiple sclerosis (2). While it shares clinical features with multiple sclerosis such as spontaneous remissions and exacerbations, the cellular and molecular basis for targeting $\mathrm{T}$ cell involvement in the skin remains unknown (2). Unlike multiple sclerosis in which a specific "antigen" has been identified (i.e., myelin basic protein) and a reproducible animal model exists (i.e., experimental allergic encephalitis), psoriasis research has been hampered by the absence of an identifiable self-antigen or animal model. Perhaps the strongest evidence supporting an autoimmune basis for psoriasis are reports that eradication of a psoriatic patient's bone marrow, and replacement with a genetically different nonpsoriatic donor, can completely cure the skin lesions $(3,4)$.

The predominant investigative pathway into autoimmunity and psoriasis has primarily been in the direction of studies of T lymphocytes (5-7), with little or no regard for the potential importance of the antigen-presenting cell populations in the dermis that possess a dendritic morphology. Members of the dendritic cell system possess an extremely potent capacity to stimulate resting $\mathrm{T}$ cell proliferation and cytokine release (810). Rather than focusing on $T$ cells, we asked whether dendritic cells isolated from skin of active untreated psoriatic lesions possess the capability of stimulating resting, autologous peripheral blood T cells. Dermal dendritic cells (DDCs) ${ }^{1}$ are increased in psoriatic lesions $(11,12)$, and we pointed out previously the potential importance of dendritic cell/T cell interaction in the pathophysiology of psoriasis (13). To determine whether psoriatic plaque (PP) DDCs possessed the capacity to stimulate spontaneous proliferation of autologous $\mathrm{T}$ cells, a method for isolating DDCs from both PP and normal skin (NN) was devised. Comparisons were made between such skin-derived as well as psoriatic blood-derived dendritic cells in autologous $\mathrm{T}$ cell proliferation assays measured with and without the addition of other $T$ cell mitogenic stimuli such as bacterialderived superantigens (SA) (staphylococcal enterotoxins A and B) and PHA. Studies involving superantigens were included because bacterial infections are frequent triggering factors for psoriatic lesion formation, and superantigens have been implicated in the pathogenesis of psoriasis $(1,14)$. Our data indicate that PP DDCs do possess a potent autostimulatory capacity to induce proliferation of resting $T$ cells which is mediated by involvement of HLA-DR, B7, and lymphocyte function associated antigen-1 (LFA-1) molecules and associated with high

1. Abbreviations used in this paper: DDCs, dermal dendritic cells; LFA1, lymphocyte function associated antigen-1; NN, normal skin; PP, psoriatic plaques; SA, superantigens. 
Table I. Immunoreactivity of DDC from PP and NN Skin

\begin{tabular}{|c|c|c|c|c|}
\hline $\begin{array}{l}\text { Specificity cluster of } \\
\text { differentiation }\end{array}$ & $\begin{array}{l}\text { Reactivity } \\
\text { (isotype) }\end{array}$ & Antibody source & $\begin{array}{c}\text { Reactivity with PP } \\
\text { DDC* }\end{array}$ & $\begin{array}{c}\text { Reactivity with NN } \\
\text { DDC* }\end{array}$ \\
\hline \multicolumn{5}{|l|}{$\mathrm{T}$ and $\mathrm{B}$ cell antigens } \\
\hline CDla & OKT-6 (IgG1) & Ortho & Moderate (15-20) & Moderate $(15-20)$ \\
\hline CD1b & 4A7.6 (IgG2a) & BIODESIGN & - & - \\
\hline CDlc & L161 (IgG1) & BIODESIGN & Strong $(>85)$ & Strong $(>85)$ \\
\hline CD3 & Leu-4 (IgG1) & Becton Dickinson & - & - \\
\hline $\mathrm{CD} 2$ & Leu-5b (IgG2a) & Becton Dickinson & - & - \\
\hline $\mathrm{CD} 7$ & Leu-9 (IgG2a) & Becton Dickinson & - & - \\
\hline CD19 & Leu-12 (IgG1) & Becton Dickinson & - & - \\
\hline CD57 & Leu-7 (IgM) & Becton Dickinson & - & - \\
\hline \multicolumn{5}{|l|}{ Myeloid antigens } \\
\hline $\mathrm{CD} 14$ & Leu-M3 (IgG1) & Becton Dickinson & Moderate (10-20) & Moderate (10-20) \\
\hline CD36 & OKM-5 (IgG1) & Ortho & Weak (10) & Weak (10) \\
\hline CD15 & Leu-M1 (IgM) & Becton Dickinson & - & - \\
\hline \multicolumn{5}{|l|}{ Adhesion molecules } \\
\hline CD11a/LFA-1 & TS $1 / 22(\operatorname{IgG} 1)$ & American Type Culture Collection & Strong $(>85)$ & Strong $(>85)$ \\
\hline CD54/ICAM-1 & 84 H 10 (IgG1) & P. Mannonini & Strong $(>85)$ & Strong $(>85)$ \\
\hline CD58/LFA-3 & TS 2.9 (IgG1) & American Type Culture Collection & Strong $(>85)$ & Strong $(>85)$ \\
\hline $\mathrm{CD} 18$ & LFA-1 $\beta$ (IgG1) & Becton Dickinson & Strong $(>85)$ & Strong $(>85)$ \\
\hline CD11b & Leu-15 (IgG2a) & Becton Dickinson & Strong $(>85)$ & Strong $(>85)$ \\
\hline VCAM-1 & (IgG1) & Genzyme & - & - \\
\hline ELAM-1 & (IgG1) & Genzyme & - & - \\
\hline CTLA-41g & (human chimera) & P. Linsley & Strong $(>85)$ & Strong $(>85)$ \\
\hline B7 & B1.1 (IgG1) & Repligen & Strong $(>85)$ & Strong $(>85)$ \\
\hline \multicolumn{5}{|l|}{ Miscellaneous } \\
\hline Factor $13 \mathrm{~A}$ & (Rabbit IgG) & Calbiochem-Novabiochem & Strong $(>85)$ & Strong $(>85)$ \\
\hline HLA-DQ & Leu-10 (IgG1) & Becton Dickinson & Strong $(>85)$ & Strong $(>85)$ \\
\hline HLA-DR & L243 (IgG2a) & Becton Dickinson & Strong $(>85)$ & Strong $(>85)$ \\
\hline $\mathrm{CD} 25$ & IL-2R (IgG1) & Becton Dickinson & Weak (10) & Weak (10) \\
\hline CD45 & HLE-1 (IgG1) & Becton Dickinson & Strong $(>85)$ & Strong $(>85)$ \\
\hline CD34 & HPCA-1 (IgG1) & Becton Dickinson & - & - \\
\hline
\end{tabular}

For reactivity, see Methods. * Weak, moderate, and strong refer to the relative intensity of staining compared with isotoype controls, -, negative immunoreactivity. The adjacent number in parentheses refers to the percentage of positively stained cells.

levels of production of IL-2 and IFN- $\gamma$, but not IL-4 or IL-10. The potential etiological as well as pathophysiological implications of these findings for psoriasis with respect to DDC/T cell interactions are discussed.

\section{Methods}

Reagents and antibodies. RPMI 1640 was supplemented with $10 \%$ FBS, $10 \mathrm{U} / \mathrm{ml}$ penicillin/streptomycin, and $50 \mu \mathrm{g} / \mathrm{ml}$ gentamicin (Gibco Laboratories, Grand Island, NY). PHA was purchased from Sigma Chemical Co. (St. Louis, MO) and used at $10 \mu \mathrm{g} / \mathrm{ml}$. Staphylococcal enterotoxins A and B were obtained from Toxin Technology Inc. (Sarasota, FL) and used at $10 \mathrm{ng} / \mathrm{ml}$ and $1 \mu \mathrm{g} / \mathrm{ml}$, respectively, in a cocktail designated SA. Detection of B7 was performed using an anti-B7 mAb (IgG1 isotype) obtained from Repligen Corp. (Cambridge, MA) or with CTLA4 Ig and control fusion protein L6 Ig (15) (Bristol-Myers Squibb Pharmaceutical Research Institute, Seattle, WA). 1C12D7 (anti-von Willebrand factor, IgG1) was a kind gift of D. Fox (University of Michigan). Additional antibodies against the following antigens listed in Table I were obtained from the following sources: CD11a and CD36 (Ortho Pharmaceutical, Raritan, NJ); CD1b and CD1c (BIODESIGN International, Kennebunkport, ME); CD3, CD2, CD7, CD19, CD57, CD14, CD15, CD18, HLA-DQ, HLA-DR, CD25, CD45, CD34, and
IgG1 isotype control antibody (Becton Dickinson and Co., Mountain View, CA); CD54/intercellular adhesion molecule-1 (obtained from P. Mannonini); vascular adhesion molecule-1 and endothelial leukocyte adhesion molecule-1 (Genzyme Corp., Cambridge, MA); and factor 13A (Calbiochem-Novabiochem, La Jolla, CA).

Cells. Keratomes of NN and untreated PP were obtained from the lower back or buttocks region in the Dermatological Treatment Center, University of Michigan, after informed consent and approval of the University of Michigan Human Subjects Committee. Epidermal and dermal sheets were prepared from keratomes, rinsed several times in PBS, cut into small pieces $(\sim 1-10 \mathrm{~mm})$, and cultured as described previously (10). Cells migrating out of the tissue sections were collected and resuspended in 1-2 $\mathrm{ml}$ of fresh medium. Further enrichment of DDCs was achieved through separation with a metrizamide gradient as described (10).

Human blood dendritic cells were isolated using standard procedures involving multistep negative selection (16). Briefly, human PBMC were enriched from heparinized peripheral blood of healthy normal donors by density centrifugation over Ficoll-Hypaque $(1.0777 \mathrm{~g} / \mathrm{ml}$; Pharmacia LKB Biotechnology Inc., Piscataway, NJ). T lymphocytes were separated by rosetting at $4^{\circ} \mathrm{C}$ with neuraminidase-treated sheep red blood cells followed by Ficoll-Hypaque sedimentation. The T cell-depleted erythrocyte-rosette negative fraction was cultured for $36 \mathrm{~h}$ at $37^{\circ} \mathrm{C}$ in $100-\mathrm{mm}$ tissue culture dishes. Nonadherent cells were panned twice on 
bacteriologic dishes coated with human immunoglobulin to deplete Fc receptor-bearing monocytes (16). Monocyte- and T cell-depleted fractions were further enriched for dendritic cells using metrizamide columns. Highly purified resting T cells were obtained as described (17). $T$ cells purified by this procedure were always $>98 \% \mathrm{CD}^{+} / \mathrm{CD}^{+}$. No HLA-DR-positive T cells were detected by flow cytometry, and these cells did not proliferate in response to PHA, verifying the absence of accessory cell contamination.

The sample sizes for the experimental protocols included five psoriatic patients (three of which also had their blood-derived dendritic cells isolated) and eight normal healthy control individuals.

Flow cytometry. All antibody dilutions and washes were in PBS containing 1\% BSA. Negative controls to rule out nonspecific staining or $\mathrm{Fc}$ receptor-mediated binding of antibodies included unrelated $\mathrm{mAb}$ of the same isotype. Cells were aliquoted at $1 \times 10^{5}$ per reaction, and all staining was performed for $25 \mathrm{~min}$ at $4^{\circ} \mathrm{C}$ using the indicated primary reagents. Secondary incubations used FITC-conjugated $F(a b)_{2}$ rabbit anti-mouse antibodies (Tago, Inc., Burlingame, CA) as described previously (10). Analysis was performed by flow cytometry using a FACScan ${ }^{\circledR}$ (Becton Dickinson and Co.) equipped with Lysis 2 software.

Proliferation assays. Proliferation assays were performed using standard techniques. Briefly, for the autologous reaction with and without either SA or PHA, gamma-irradiated stimulator dendritic cells $(3,000 \mathrm{rad})$ were cocultured at the indicated concentrations with $5 \times 10^{4}$ purified $\mathrm{T}$ cells in 96-well round-bottom culture plates (Costar Corp., Cambridge, MA) in $200 \mu$ l of RPMI 1640 plus 10\% FBS. Cells were pulsed for the final $18 \mathrm{~h}$ of the incubation period ( $5 \mathrm{~d}$ for autologous reactions without SA or PHA and $3 \mathrm{~d}$ with addition of SA or PHA) with $1 \mu \mathrm{Ci} /$ well of $\left[{ }^{3} \mathrm{H}\right]$ thymidine (New England Nuclear, Boston, MA) to assess proliferation. Values are expressed as the mean counts per minute \pm SD of triplicate wells. To control for soluble factors within PP skin, psoriatic dermal fragment-conditioned medium (48-72 h) was added back at a 1:1 ratio with fresh RPMI plus $10 \%$ FCS to psoriatic blood-derived dendritic cell reactions. For blocking experiments mAbs or appropriate isotype controls were added to the T cells at the indicated concentrations and remained in the cultures throughout the incubation period.

Detection of cytokines. Supernatants from the dendritic cell/T cell reactions were collected at 24 and $72 \mathrm{~h}$ and stored at $-80^{\circ} \mathrm{C}$. ELISAs for IL-2 and IL-4 were performed using Quantikine immunoassay kits purchased from R\&D Systems, Inc. (Minneapolis, MN). ELISAs for IFN- $\gamma$ were performed using a kit purchased from Genzyme Corp. All protocols were performed in duplicate wells according to manufacturers' instructions. The lowest limit of detection for these cytokines was $1 \mathrm{pg} /$ $\mathrm{ml}$. IL-10 was assayed using a sensitive and specific ELISA (kindly provided by Dr. S. Kunkel and Dr. R. Strieter, University of Michigan) which has a lower limit of detection of $10 \mathrm{pg} / \mathrm{ml}$.

Data analysis. For each experimental protocol, a representative result is portrayed for a single individual subject's reaction. Consistent differences between all psoriatic patients and normal, healthy control individuals were observed for all assays. Statistical analysis using Student's $t$ test (two-sided) was performed, and the results were considered significant when $P<0.01$.

\section{Results}

Purification of dendritic cells from skin and blood samples. As reported previously (10), this purification schema reliably yields highly purified preparations of dendritic cells from PP and NN skin, as well as blood samples. Typical yields of DDCs from PP skin were $0.5-1.0 \times 10^{6}$ cells and $0.1-0.5 \times 10^{6}$ cells from NN skin; with $\sim 0.5-1.0 \times 10^{6}$ blood dendritic cells obtained from $100 \mathrm{ml}$ of peripheral blood of psoriatic patients. Examination of cultured DDCs from different sources by phasecontrast microscopy revealed an identical appearance of large mononuclear cells that had numerous elongate dendritic processes eminating from the cytoplasm, giving the cells a fuzzy appearance.

Immunophenotypic characterization of various dendritic cell populations. Dendritic cells isolated from skin and blood of psoriatic patients and from skin of normal individuals were immunophenotyped using a panel of reagents (Table I). With this panel designed to detect 26 antigens, the immunophenotypic profile for both PP skin - and NN skin-derived DDCs including positive and negative results was indistinguishable. Comparable staining results included both relative intensity and percentage of positive DDCs isolated from both PP and NN skin. A representative flow cytometry profile reveals that DDCs from PP skin and NN skin possessed a uniform population with high cell-surface levels of HLA-DR, CD11a (LFA-1), and B7 (Fig. 1). No quantitative differences in any of these three important cell-surface molecules could be detected when comparing either NN skin or PP skin DDCs.

Autologous resting $T$ cell proliferation induced by DDCs. In spite of an identical phase-contrast microscopic appearance and immunophenotypic profile of expression for HLA-DR, B7, and LFA-1 for the various dendritic cells, differences in their relative stimulatory capacity of autologous $\mathrm{T}$ lymphocytes were observed. PP skin-derived DDC, but not psoriatic blood-derived dendritic cells, strongly stimulated autologous $\mathrm{T}$ cell proliferation. PP skin-derived DDCs were also superior in their ability to stimulate autologous $\mathrm{T}$ cell proliferation compared with either psoriatic blood-derived dendritic cells or NN skinderived DDCs (Fig. 2). It should be noted that all of the cultured dendritic cell preparations possessed the capacity to induce low-level proliferation of resting $\mathrm{T}$ cells in agreement with a previous observation (8), but PP skin-derived DDCs were significantly more potent as stimulators compared with the other dendritic cell population studied at all concentrations used of DDCs. As few as 50 DDCs per well from PP skin resulted in autologous $T$ cell proliferation ( $T$ cell/DDC ratio of 1,000:1). When 500 dendritic cells were used, the PP skin-derived DDCs induced a level of $T$ cell proliferation of $19 \times 10^{3} \mathrm{cpm}$ compared with NN skin-derived DDC level of $3 \times 10^{3} \mathrm{cpm}(P<0.01)$. Thus, for the psoriatic and normal individual results shown in Fig. 2, the PP skin-derived DDC/T cell proliferation was sixfold greater than the NN skin-derived DDC/T cell proliferation. We ascribed the enhanced autoreactivity in these reactions primarily to stimulator DDCs, rather than the responder T cells, because of the results using blood-derived dendritic cells as stimulators. As can be seen, blood-derived dendritic cells from psoriatic patients are relatively weak compared with PP skinderived DDCs when using the same responder $T$ cell population. Thus, while it is clear that there are autoreactive $T$ cells in the peripheral blood of psoriatic patients (18), their relative level of stimulation is clearly dependent on whether PP skinderived versus blood-derived dendritic cells are used as stimulator cells. The pooled mean levels of $\mathrm{T}$ cell proliferation induced by various dendritic cell populations isolated from all of the subjects studied when $5 \times 10^{3}$ dendritic cells were combined with $5 \times 10^{4}$ autologous $\mathrm{T}$ cells are as follows: peripheral blood-derived dendritic cells from psoriatic patients $65,572 \pm 5,840 \mathrm{cpm}$ (range 57,560-74,000 cpm); peripheral blood-derived dendritic cells from psoriatic patients $6,967 \pm 1,077 \mathrm{cpm}$ (range 5,300-9,000 cpm); DDC-NN $7,960 \pm 1,496 \mathrm{cpm}$ (range 4,500-11,000 cpm). We conclude that PP skin-derived DDCs were significantly more effective as 


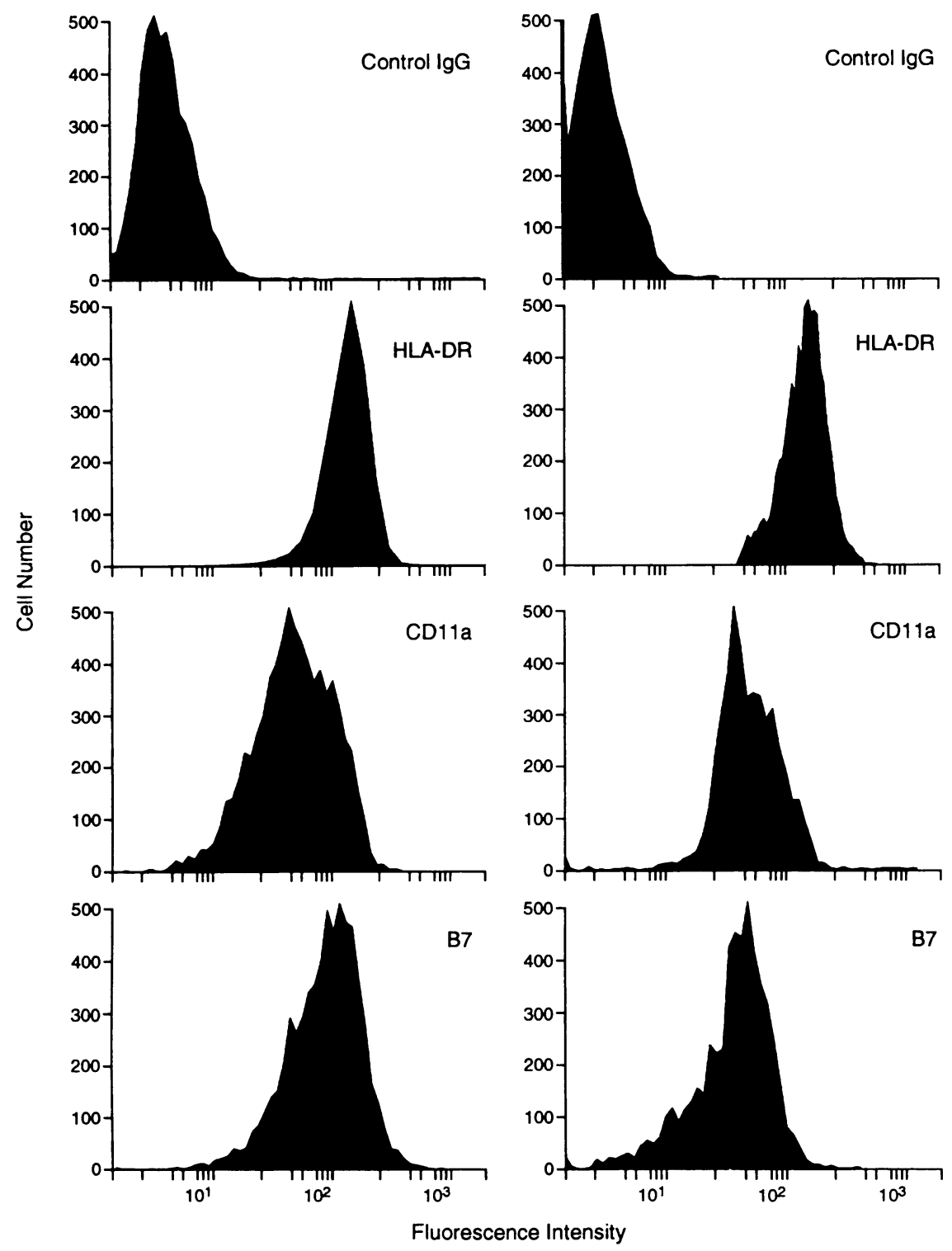

Figure 1. Flow cytometric analysis of DDCs isolated from NN (left) and PP skin (right). Cultured DDCs from these different skin sites were harvested and immunostained as described in Methods, using pooled irrelevant $\mathrm{IgG1}$ isotype control, as well as HLADR, CD11a, and B7. Note the strong and equivalent reactivity of DDCs obtained from both skin sites which are composed of a uniform population of cells for the three surface antigens compared with control antibody staining. stimulator cells compared with either psoriatic blood-derived dendritic cells or NN skin-derived DDCs $(P<0.01)$.

To further assess the relative stimulating capacity of dendritic cells (used at 500 cells/well) obtained from different sources, autologous $\mathrm{T}$ cell responses in the presence of PHA or SA were also measured, and a representative result is portrayed in Fig. 3. While highly purified resting $\mathrm{T}$ cells from blood do not proliferate directly to either PHA or SA, when dendritic cells are added, vigorous $\mathrm{T}$ cell proliferation ensues. The $\mathrm{T}$ cell responses depicted for these reactions include both a direct autologous stimulation by dendritic cells as well as an additional component secondary to the PHA or SA. It should be noted that even though the psoriatic blood-derived dendritic cells and the NN skin-derived DDCs were relatively weak stimulators of $\mathrm{T}$ cell proliferation in the absence of PHA or SA, upon addition of exogenous $\mathrm{T}$ cell mitogens, these dendritic cells functioned $\sim 50 \%$ as effectively as accessory cells compared with PP skin-derived DDCs. These results indicate that PP skin-derived DDCs are only superior to the other dendritic cells in the absence of added exogenous mitogens and confirm the overall responsiveness of circulating $T$ cells from normal and psoriatic patients.

Addition of psoriatic dermal fragment conditioned medium did not augment blood-derived dendritic cell stimulatory capacity. Because it is established that certain cytokines such as GM-CSF and IL-1 (but not TNF $\alpha$ ) can enhance the ability of dendritic cells to stimulate resting T cells (19-22), we sought to determine if psoriatic dermal fragments were producing cytokines during the initial 2-3-d isolation period that could have mediated the relative superior ability of PP skin-derived DDC to stimulate T cells compared with blood-derived dendritic cells obtained from the same individual. Figs. 2 and 3 ( far right) reveal that adding conditioned medium from the psoriatic dermal fragments to blood-derived dendritic cell reactions had no effect on the stimulating capacity of these dendritic cells when autologous $\mathrm{T}$ cells were added either in the absence or presence of SA or PHA. 


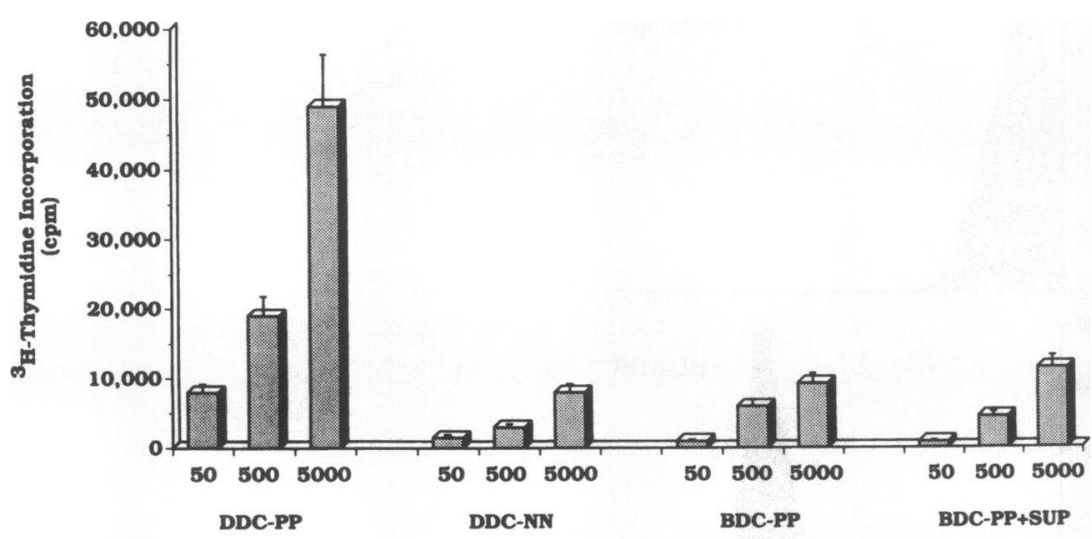

Number of Dendritic Cells/Well Used as Stimulators With Autologous T-Lymphocytes
Figure 2. Concentration-dependent increase of autoreactivity between DDCs and resting peripheral blood T lymphocytes. Autologous purified T cells $\left(5 \times 10^{4}\right)$ were combined with increasing numbers of DDCs $(50,500$, and 5,000 cells/well) isolated from either PP skin, NN skin, or blood dendritic cells of a psoriatic patient ( $B D C-P P)$. In some experiments, conditioned medium from psoriatic dermal fragments was combined 1:1 with psoriatic blood-derived dendritic cells before addition of autologous $\mathrm{T}$ cells $(B D C-P P+S U P)$. In the absence of dendritic cells, $\mathrm{T}$ cell $\left[{ }^{3} \mathrm{H}\right]$ thymidine incorporation was $<500 \mathrm{cpm}$ in all experiments, as was the incorporation for $5 \times 10^{3} \mathrm{DDCs}$ alone. Note that for all stimulator/responder ratios, PP DDC were six times more potent in inducing the spontaneous proliferation of $\mathrm{T}$ cells, and there was no increase in $T$ cell proliferation upon addition of conditioned medium. The data shown are representative of separate experiments using five different psoriatic patients and eight different normal, control individuals.
Antibody blocking studies of autologous $T$ cell/dendritic cell reaction. To examine the molecular basis by which PP skin-derived DDCs stimulated resting $\mathrm{T}$ cell proliferation, the DDCs were preincubated with various blocking reagents. Fig. 4 reveals a representative result demonstrating significant inhibition of this reaction in a concentration-dependent fashion when the DDC surface molecules HLA-DR, or B7, or LFA-1 were blocked (identical blocking results were obtained for all patients; data not shown). The anti-HLA-DR mAb was particularly effective at inhibiting this reaction (producing $>90 \%$ inhibition at $0.1 \mu \mathrm{g} / \mathrm{ml}$ ), supporting an important role for this class II MHC molecule in stimulating the $\mathrm{T}$ cell proliferative response.

Characterization of cytokines produced during dendritic cell/T cell stimulation. In addition to vigorous $\mathrm{T}$ cell proliferation induced by autologous PP skin-derived DDCs, we next asked whether the cytokine production profile in stimulated $\mathrm{T}$ cells resembled either a Th1 or Th2 type response. The classification of murine $T$ cell subsets into Th1 versus Th2 types is based on their cytokine production profiles (23). Thus, 24- and 72-h supernatants were analyzed to detect IL-2 and IFN- $\gamma$ (Th1 type cytokines) or IL-4 and IL-10 (Th2 type cytokines). Overall, the IL-2 levels detected under various conditions for each of the dendritic cells used as stimulator cells correlated fairly well to the relative degree of $\mathrm{T}$ cell proliferation as assessed by $\left[{ }^{3} \mathrm{H}\right]$ thymidine incorporation (Fig. 5). Thus, in the absence of added PHA or SA, PP skin-derived T cell stimulation was accompanied by four to eight times more IL-2 compared with NN skin-derived DDCs, in both 24- and 72-h samples. Upon addition of either SA or PHA, there were increases in IL-2 levels of production at both time points for both NN skin- and PP skin-derived DDCs. Fig. 6 portrays a representative result for PP skin- and NN skin-derived DDCs. When PP skinderived DDCs were used without exogenous mitogens, the high levels of IL-2 were accompanied by relatively high levels of IFN- $\gamma$ (Fig. $6 \mathrm{~A}$ ) detected in both 24 - and 72-h supernatants (ranging from 270 to $380 \mathrm{pg} / \mathrm{ml}$ ). These cytokine levels contrasted sharply with the relatively low to absent levels (always $<10 \mathrm{pg} / \mathrm{ml}$ ) of detectable IL-4 (Fig. 6 B). No IL-10 was detected in any supernatants at either time point (data not

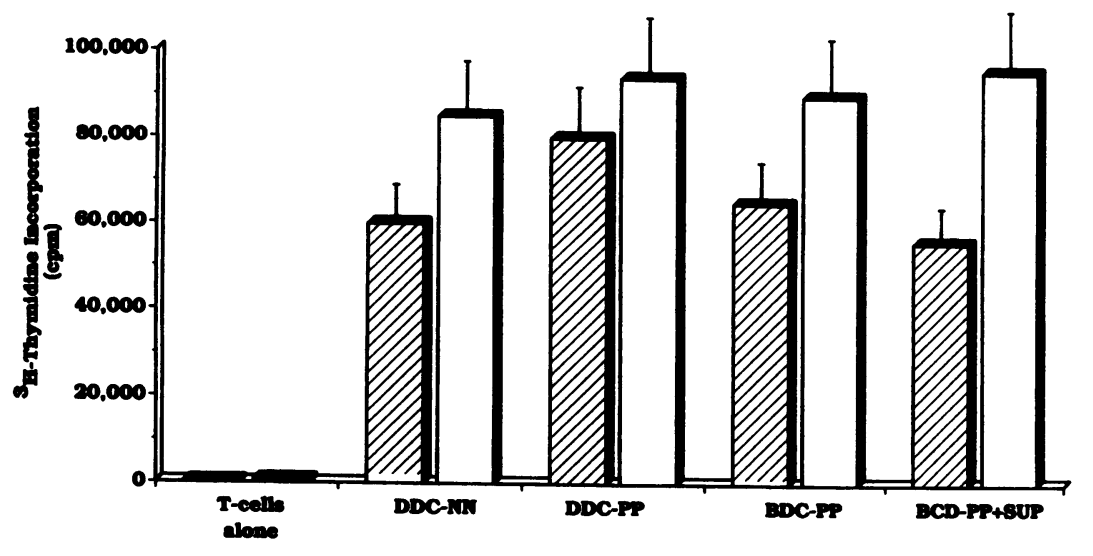

Type of Edimninter Colls Used (600 Amtologens Dendritle Cells/Nieln)
Figure 3. Dendritic cells (500 per well) isolated from either PP skin, NN skin, or peripheral blood of psoriatic patients function as effective accessory cells for autologous $\mathrm{T}$ cells $\left(5 \times 10^{4}\right.$ per well $)$ with addition of PHA (hatched bars) or SA (white bars). Note that purified $T$ cells without dendritic cells do not respond to SA or PHA and that PP skin-derived DDCs were not as superior in this assay as compared with results portrayed in absence of exogenous mitogens as described in the legend to Fig. 2. 


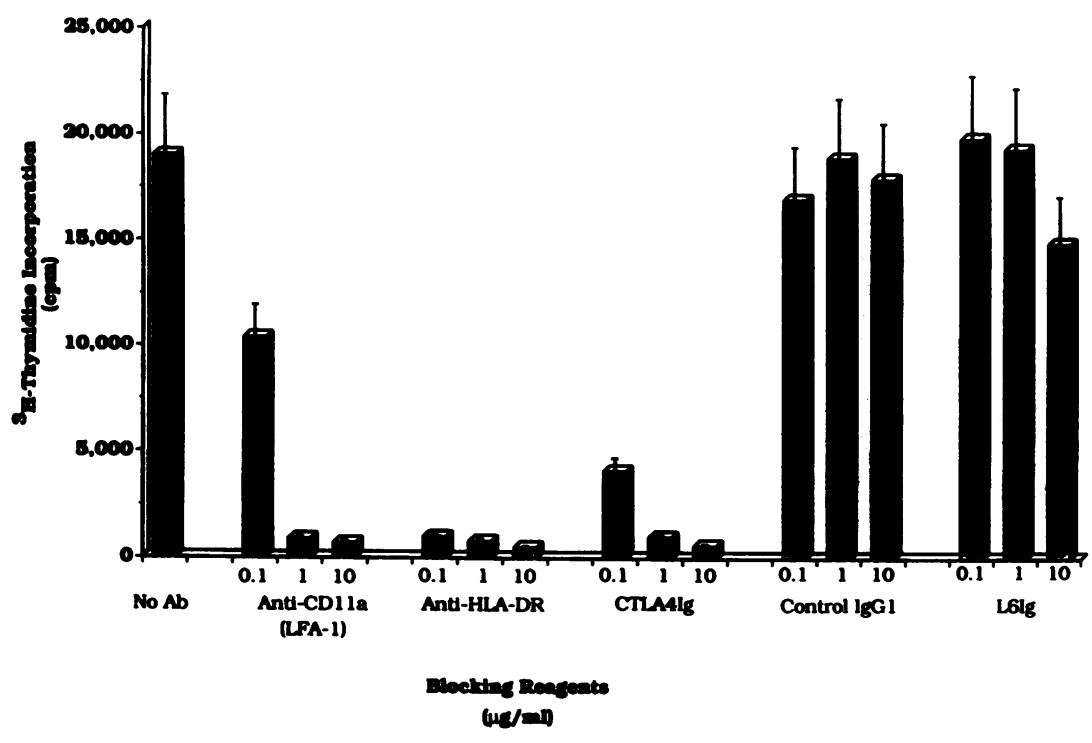

Figure 4. Antibodies directed against CD11a (LFA1), HLA-DR, or addition of CTLA4 Ig (to block B7/CD28 interaction) inhibit in a concentrationdependent fashion (used at $0.1,1.0$, and $10 \mu \mathrm{g} / \mathrm{ml}$ ) autologous $\mathrm{T}$ cell proliferation induced by PP skinderived DDCs (used at 500 cells/well) compared with control wells. There was no significant inhibition upon addition of either $\mathrm{L6}$ Ig or control IgG (anti-von Willebrand factor antibody). shown). Upon analysis of supernatants for reactions to which PHA had been added, there was a striking increase in IL-4 levels for both PP skin-derived and NN skin-derived DDCs (Fig. $6 \mathrm{~A}$ ), with lesser increases in $\mathrm{IL}-4$ production after addition of SA (Fig. $6 \mathrm{~A}$ ). When SA was added, similar increases in IFN- $\gamma$ levels were observed compared with the PHA-induced response (Fig. $6 \mathrm{~B}$ ). After addition of either PHA or SA, no $\mathrm{IL}-10$ was detected, even though control reactions run in parallel composed of Ficoll-Hypaque interface mononuclear cells stimulated with SA produced IL-10. Thus, the cytokine production profile for the interaction between PP skin-derived DDCs and autologous $\mathrm{T}$ cells in the absence of exogenous mitogens resembled the murine Th1 type of cytokines that promote $\mathrm{T}$ cellmediated immunity rather than B cell help as is seen in a humoral response. This preferential induction of IL-2 and IFN$\gamma$ was not due to the absence of responder T cells belonging to the Th2 subset, because addition of PHA and SA led to the production of IL-4 by these same peripheral blood-derived T cells.

\section{Discussion}

It has been $20 \mathrm{yr}$ since Steinman and Cohn (24) first described a novel cell type with dendritic morphology in the spleen. Since this observation, dendritic cells have been identified in blood (16) and reside in many other tissue sites including the dermis of human skin (11). Cultured dendritic cells are well known for their unique ability to stimulate resting $\mathrm{T}$ lymphocytes (9). The current results in which dendritic cells that have migrated out of small tissue fragments were capable of stimulating autologous resting $\mathrm{T}$ cells confirm these original observations regarding the potent stimulatory capacity of cells possessing a dendritic morphology and high levels of class II MHC antigens. However, we discovered that, relative to $\mathrm{NN}$ skin or peripheral blood, DDCs isolated from PP skin are capable of stimulating $T$ cells approximately eight times greater than equal numbers of the other dendritic cells bearing identical levels of class II MHC and B7 antigens. It is of interest and potential pathophysiological relevance that the profile of cytokines produced when PP skin-derived DDCs autostimulated T cells was a Th1 type response, because we have characterized the cytokine network of psoriatic plaques in vivo and have concluded that it also represents a Th1 type profile (25). Using polymerase chain reaction analysis of PP skin, we consistently observed detectable levels of IL- 2 and IFN- $\gamma$ mRNAs, but not IL-4 or IL-10 mRNAs (25), which is similar to the current functional cytokine production profiles using PP DDC and T cells (Figs. 5 and 6). Furthermore, the ability of PP DDC to induce 5-10 times more IFN-

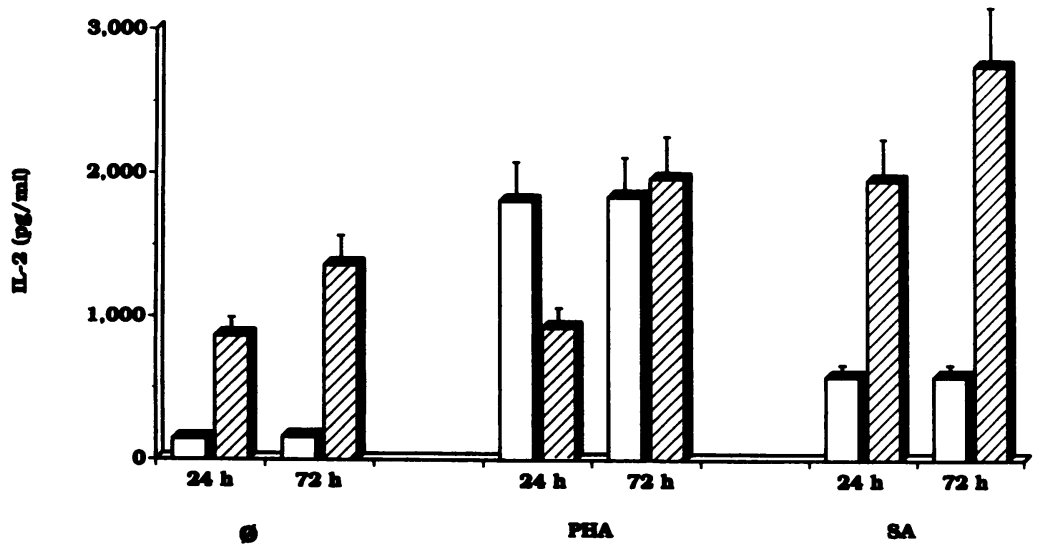

Figure 5. IL-2 production by autologous $\mathrm{T}$ cells stimulated by DDCs ( 500 cells/well) either in the absence or presence of SA or PHA. Note that the 24- and 72-h levels detected in the supernatants tend to parallel $\mathrm{T}$ cell proliferation results portrayed in Figs. 2 and 3. Supernatants were analyzed by ELISA as described in Methods. White bars, NN skin-derived DDCs; hatched bars, PP skin-derived DDCs. 

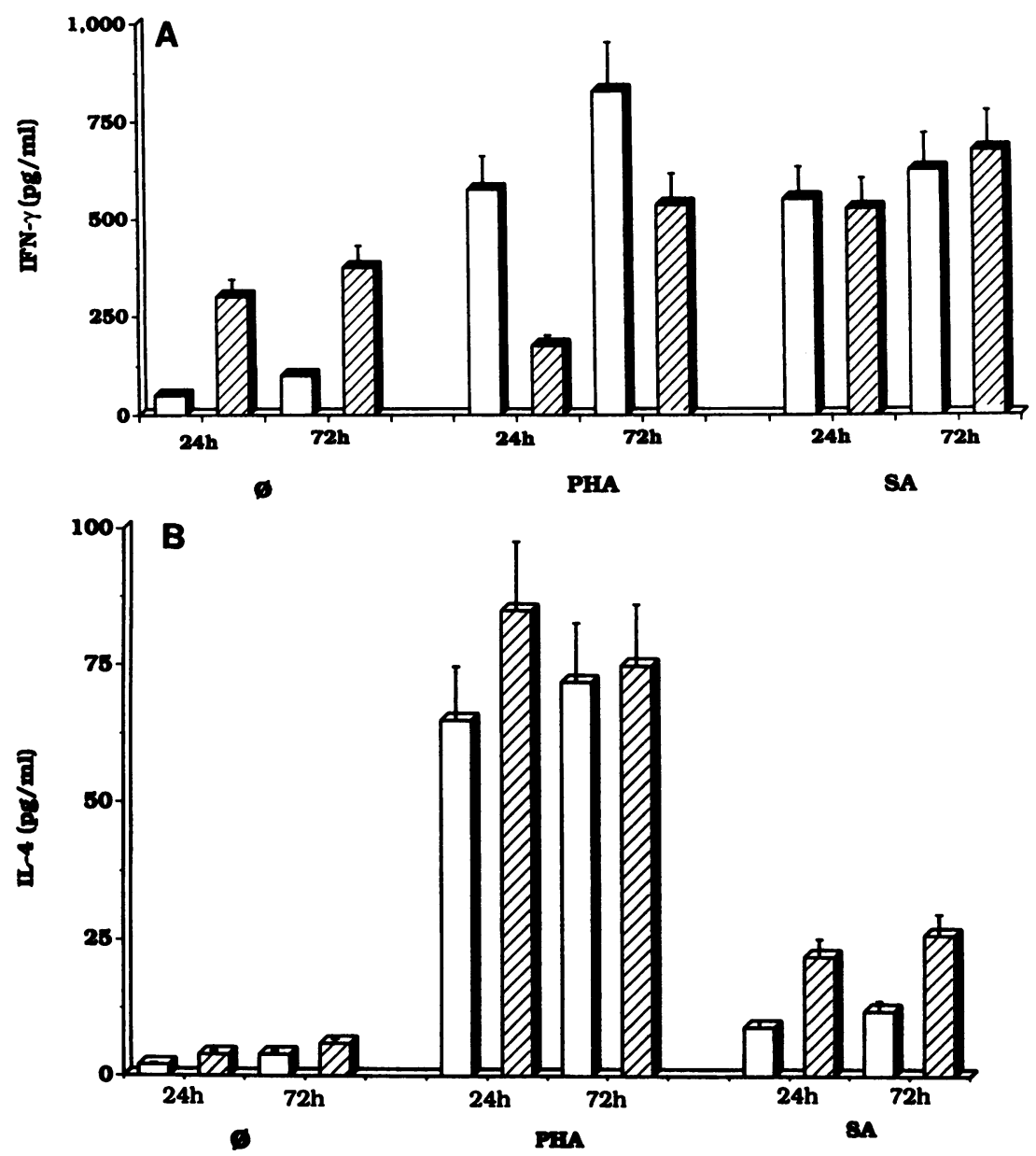

Figure 6. Induction of cytokines IFN- $\gamma(A)$ and IL$4(B)$ produced during autologous reactions at 24 and $72 \mathrm{~h}$ between $\mathrm{T}$ cells and either NN skin-derived (white bars) or PP skin-derived (hatched bars) DDCs ( 500 cells/well) in the absence and presence of SA or PHA. Note that in the absence of exogenous mitogens, PP skin-derived DDCs promoted greater $\mathrm{T}$ cell production of the Th1 cytokine IFN- $\gamma$ compared with NN skin-derived DDCs, but neither source of DDCs stimulated $>5$ $\mathrm{pg} / \mathrm{ml}$ of IL-4. However, upon addition of either PHA or SA, the responder T cells were capable of producing IL-4. $\gamma$ in resting T cells compared with NN DDC is of particular relevance because intradermal injection of IFN- $\gamma$ can induce psoriasis in symptomless skin of genetically predisposed individuals (26). The current results are also in agreement with the existence of autoreactive $\mathrm{T}$ cells present in psoriatic patients as detected by previous investigators $(5-7,18)$.

Since DDCs express high cell-surface levels of the class II MHC antigen HLA-DR, as well as the important costimulatory molecule B7, it was not surprising that blocking reagents targeted at these molecules inhibited the reaction (27). Furthermore, another group has observed that B7-positive antigen-presenting cells primarily promote a Th1 type cytokine production profile by responding $\mathrm{T}$ cells (28). Even though the dendritic cells isolated from various locations were potent accessory cells when the T cell mitogens PHA or SA were added, it was the PP skin-derived DDCs that were distinguished in the autologous reactions devoid of exogenous lectin or superantigens. To determine whether the other dendritic cells could serve as potent accessory cells upon addition of $\mathrm{T}$ cell mitogens, identical autologous reactions were set up using PHA and SA. These reactions verified that dendritic cells isolated from $\mathrm{NN}$ skin or psoriatic blood could function as potent accessory cells and emphasized the relative superiority of PP skin-derived DDC in the autoreactive proliferation of $\mathrm{T}$ cells in the absence of PHA or SA.

To control for the possibility that PP skin-derived DDCs were better stimulators compared with $\mathrm{NN}$ skin-derived $\mathrm{T}$ cells because of relative differences in levels of circulatory autoreac- tive $\mathrm{T}$ cells in the blood, we included studies of blood-derived dendritic cells isolated from psoriatic patients. While in both circumstances PP skin-derived DDCs and blood-derived DDCs did stimulate autologous $\mathrm{T}$ cell proliferation (confirming the existence of circulating autoreactive $T$ cells $)(5-7,18)$, the skin - derived DDCs were always capable of greater $\mathrm{T}$ cell stimulation compared with blood-derived DDCs using the same individual $\mathrm{T}$ cells as responders. Thus, these results suggest that PP skin-derived DDCs may also bear $\mathrm{T}$ cell mitogenic signals beyond HLA-DR and B7. Additionally, the increased autostimulatory capacity of PP DDCs may be due to increased expression of other costimulatory molecules besides B7 or the other molecules examined in Table $I$. While the nature of this activating signal is not clear, it could represent either an exogenously acquired antigen or a modified self-endogenously derived antigen. Studies are in progress to obtain sufficient numbers of PP skin-derived DDCs to elute the class II MHC-associated peptides to determine the identity of such a $\mathrm{T}$ cell stimulatory signal. In two psoriatic patients studied, DDCs isolated from lesion-free skin produced approximately the same relatively low level of autostimulation of T cells as compared with NN skinderived DDCs (data not shown), suggesting that the appropriate signals necessary to provoke a strong immunostimulatory reaction are not present at such sites of symptomless skin.

To further explore whether the lack of stimulation by psoriatic blood-derived dendritic cells relative to PP skin-derived DDCs could be due to the possibility that the psoriatic skin 
milieu was providing a diffusible factor that upregulated autostimulatory potential of dendritic cells, add-back experiments were performed. As shown in Figs. 2 and 3, addition of 1:1 conditioned medium obtained from the psoriatic dermal fragments did not enhance the ability of blood-derived dendritic cells to stimulate autologous T cells. In the past, cytokines such as GMCSF have been particularly noted for their ability to promote the immunological potency of freshly isolated epidermal dendritic cells, most likely by upregulating their B7 expression (19$22,29)$. However, we believe this possibility is unlikely to adequately explain our results for three reasons. First, we did not use freshly isolated cells, and all dendritic cells were cultured for equivalent periods. Second, all of the dendritic cells expressed equivalent levels of HLA-DR, B7, and LFA-1 (as well as the other antigens noted in Table I). Third, adding back the conditioned medium from psoriatic dermal fragments did not enhance the autostimulatory capacity of blood-derived dendritic cells.

In conclusion, our results indicate that PP skin-derived DDCs possess a strong capacity to stimulate autologous $\mathrm{T}$ cells to spontaneously proliferate and to produce IL-2 and IFN- $\gamma$, but not $\mathrm{IL}-4$. We verified that the responder $\mathrm{T}$ cell population could produce $\mathrm{IL}-4$ by the experiments in which SA or PHA were added that resulted in significant IL-4 production (Fig. $6 \mathrm{~B}$ ). Thus, not only do PP skin-derived DDCs induce the spontaneous proliferation of $\mathrm{T}$ cells, but the cytokine profile in the absence of SA or PHA favors responder T cells preferentially secreting IL- 2 and IFN- $\gamma$. Given the self-reinforcing nature of Th1 versus Th2 type cytokines, it is tempting to speculate that our in vivo results of a Th1 type cytokine network include an immunological component derived from the kind of DDC/ $\mathrm{T}$ cell interactions described in this report.

\section{Acknowledgments}

The authors thank Carolyn Peterson for assisting in tissue procurement.

This work was supported by National Institutes of Health grants AR40065, AR-01823, AR-40488 (B. J. Nickoloff), and ISPO AR-41703 (L. A. Turka).

\section{References}

1. Nickoloff, B. J. 1991. The cytokine network in psoriasis. Arch. Dermatol. 127:871-884.

2. Steinman, L. 1993. Autoimmune disease. Sci. Am. 267:107-114.

3. Eedy, D. J., D. Burrows, J. M. Bridges, and F. C. C. Jones. 1990. Clearance of severe psoriasis after allogenic bone marrow transplantation. Br. Med. J. 300:908-909.

4. Jowitt, S. N., and J. A. L. Yin. 1990. Psoriasis and bone marrow transplantation. Br. Med. J. 300:1398-1399.

5. Nikaein, A., C. Phillips, S. C. Gilbert, D. Savino, A. Silverman, M. J. Stone, and A. Menter. 1991. Characterization of skin infiltrating lymphocytes in patients with psoriasis. J. Invest. Dermatol. 96:3-9.

6. Takashima, A., and A. Morita. 1991. Genomic, phenotypic, and functional analysis of $\mathrm{T}$ cells in patients with psoriasis undergoing systemic cyclosporin $\mathrm{A}$ treatment. J. Invest. Dermatol. 96:376-382.

7. Nikaein, A., L. Morris, C. Phillips, M. Soliman, G. Ordonez, A. Silvermen, M. J. Stone, and A. Menter. 1993. Characterization of T cell clones generated from skin of patients with psoriasis. J. Am. Acad. Dermatol. 28:551-557.
8. Nussenzweig, M. C., and R. M. Steinman. 1980. Contribution of dendritic cells to stimulation of the murine syngeneic mixed leukocyte reaction. $J$. Exp. Med. 151:1196-1212.

9. Steinman, R. M. 1991. The dendritic cell system and its role in immunogenicity. Annu. Rev. Immunol. 9:271-296.

10. Nestle, F. O., X. G. Zheng, C. B. Thompson, L. A. Turka, and B. J. Nickoloff. 1993. Characterization of dermal dendritic cells obtained from normal human skin reveals phenotypic and functionally distinctive subsets. J. Immunol. 151:6535-6545.

11. Cerio, R., C. E. M. Griffiths, K. D. Cooper, B. J. Nickoloff, and J. T. Headington. 1989. Characterization of factor XIIIa positive dermal dendritic cells in normal and inflamed skin. Br. J. Dermatol. 121:421-431.

12. Van Nur, F., V. Zemelman, R. Cerio, J. Langtry, and R. C. Staugher 1993. The role of factor XIII a-positive dermal dendrocytes in HIV-1 positive psoriasis. Br. J. Dermatol. 128:29-33.

13. Nickoloff, B. J., and C. E. M. Griffiths. 1990. Lymphocyte trafficking in psoriasis. A new perspective emphasizing the dermal dendrocyte with active recruitment mediated via endothelial cells followed by intra-epidermal T-cell activation. J. Invest. Dermatol. 95(Suppl.):355-375.

14. Leung, D. Y. M., P. Walsh, R. Giorns, and D. A. Norris. 1993. A potential role for superantigens in the pathogenesis of psoriasis. J. Invest. Dermatol. 100:225-228.

15. Linsley, P. S., W. Brady, M. Umes, L. S. Grosmaire, N. K. Damle, and J. A. Ledbetter. 1991. CTLA-4 is a second receptor for the B cell activation antigen B7. J. Exp. Med. 174:561-569.

16. Freudenthal, P. S., and R. M. Steinman. 1990. The distinct surface of human blood dendritic cells as observed after an improved isolation method. Proc. Natl. Acad. Sci. USA. 87:7698-7702.

17. Nickoloff, B. J., R. S. Mitra, J. Green, X. G. Zheng, Y. Shimizu, C. Thompson, and L. A. Turka. 1993. Accessory cell function of keratinocytes for superantigens: dependence on lymphocyte function-associated antigen-1/intercellular adhesion molecule-1 interaction. J. Immunol. 150:2148-2159.

18. Steinmuller, D., A. R. Zinsmeister, and R. S. Rogers. 1988. Cellular autoimmunity in psoriasis. J. Autoimmun. 1:279-298.

19. Schuler, G., and R. M. Steinman. 1985. Murine epidermal Langerhans cells mature into potent immunostimulatory dendritic cells in vitro. J. Exp. Med. 161:526-546.

20. Witmer-Pack, M. D., W. Olivier, J. Valinsky, G. Schuler, and R. M. Steinman. 1987. Granulocyte/macrophage colony-stimulating factor is essential for the viability and function of cultured murine epidermal Langerhans cells. $J$. Exp. Med. 166:1484-1498.

21. Heufler, C., F. Koch, and G. Schuler. 1988. Granulocyte/macrophage colony-stimulating factor and interleukin 1 mediate the maturation of murine epidermal Langerhans cells into potent immunostimulatory dendritic cells. J. Exp. Med. 167:700-705.

22. Koch, F., C. Heufler, E. Kämpgen, D. Schneeweiss, G. Böck, and G. Schuler. 1990. Tumor necrosis factor $\alpha$ maintains the viability of murine epidermal Langerhans cell in culture, but in contrast to granulocyte/macrophage colonystimulating factor, without inducing their functional maturation. J. Exp. Med. 171:159-171.

23. Mosmann, T. R., H. Cherwinski, M. W. Bond, M. A. Giedlin, and R. L. Coffman. 1986. Two types of murine helper $T$ cell clones. I. Definition according to profiles of lymphokine activities and secreted proteins. J. Immunol. 136:23482357.

24. Steinman, R. M., and Z. A. Cohn. 1973. Identification of a novel cell type in peripheral lymphoid organs of mice. I. Morphology, quantification, tissue distribution. J. Exp. Med. 137:1142-1153.

25. Uyemura, K., M. Yamamura, D. P. Fivenson, R. L. Modlin, and B. J. Nickoloff. 1993. The cytokine network in lesional and lesion-free psoriatic skin is characterized by a T-helper type 1 cell-mediated response. J. Invest. Dermatol. 101:701-705.

26. Fierlbeck, G., G. Rasser, and C. Muller. 1990. Psoriasis induced at the injection site of recombinant interferon gamma. Arch. Dermatol. 126:351-355.

27. June, C. H., J. A. Ledbetter, P. J. Linsley, and C. B. Thompson. 1990. Role of CD28 receptor in T-cell activation. Immunol. Today. 11:211-218.

28. Tan, P., C. Anasetti, J. A. Hansen, J. Melrose, M. Brunvand, J. Bradshaw, J. A. Ledbetter, and P. S. Linsley. 1993. Induction of alloantigen-specific hyporesponsiveness in human $\mathrm{T}$ lymphocytes by blocking interaction of CD28 with its natural ligand B7/BB1. J. Exp. Med. 177:165-173.

29. Larsen, C. P., S. C. Ritchie, T. C. Pearson, P. S. Linsley, and R. P. Lowry. 1992. Functional expression of the costimulatory molecule, B7/BB1 on murine dendritic cell populations. J. Exp. Med. 176:1215-1220. 